\title{
Investigating the effect of physiological need states on palatability and motivation using microstructural analysis of licking
}

Running title: Lick microstructure and physiological states

Authors: Fabien Naneix ${ }^{a}$, Kate Z. Peters ${ }^{b}$, James E. McCutcheon ${ }^{a, c}$

\author{
a Dept. of Neuroscience, Psychology \& Behaviour, University of Leicester, Leicester, UK \\ b Dept. of Anatomy and Neurobiology, University of Maryland School of Medicine, Baltimore, \\ MD, USA \\ c Dept. of Psychology, UiT The Arctic University of Norway, Troms $\varnothing$, Norway
}

Corresponding author: JE McCutcheon (j.mccutcheon@uit.no; @jaimemcc)

\section{Author's contribution:}

FN and JEM designed research; FN performed research, FN, KZP and JEM analyzed data; FN, KZP and JEM wrote the manuscript. 


\section{ABSTRACT}

The study of consummatory responses during food intake represents a unique opportunity to investigate the physiological, psychological and neurobiological processes that control ingestive behavior. Recording the occurrence and temporal organization of individual licks across consumption, also called lickometry, yields a rich data set that can be analyzed to dissect consummatory responses into different licking patterns. These patterns, divided into trains of licks separated by pauses, have been used to deconstruct the many influences on consumption, such as palatability evaluation, incentive properties, and post-ingestive processes. In this review, we describe commonly used definitions of licking patterns and how various studies have defined and measured these. We then discuss how licking patterns can be used to investigate the impact of different physiological need states on processes governing ingestive behavior. We also present new data showing how licking patterns are changed in an animal model of protein appetite and how this may guide food choice in different protein-associated hedonic and homeostatic states. Thus, recording lick microstructure can be achieved relatively easily and represents a useful tool to provide insights, beyond the measurement of total intake, into the multiple factors influencing ingestive behavior.

\section{HIGHLIGHTS}

- Analysis of lick microstructure provides useful information on incentive and hedonic processes underlying ingestive behavior

- Different physiological need states, such as hunger, impact licking patterns

- Protein appetite increases palatability of protein-containing food, which may be used to orient food-related behaviors

\section{KEYWORDS}

Lick microstructure; palatability; appetitive; consummatory; taste 


\section{INTRODUCTION}

Food intake and its control requires the integration of multiple peripheral signals including those related to homeostatic state, food palatability, sensory properties of the food, and postingestive processes (Berthoud, 2012; Schwartz et al., 2000; Volkow et al., 2011). These signals interact with central representations of food (learned and innate food values) to influence feeding and food-related behaviors. The complex interaction of central and peripheral signals will, for instance, promote the consumption of palatable food (e.g. sweet) but induce the avoidance of other stimuli (e.g. bitter foods, which are often a signal of toxicity). Moreover, it will also allow food choice to be flexibly expressed depending on current motivational drives such as the need for specific nutrients.

Food-related behaviors can be divided into two broad mechanisms. First, motivational processes allow an organism to engage behavioral responses to pursue rewarding foods or, in contrast, to avoid aversive stimuli. This group of behaviors is on a continuum encompassing both appetitive (approach and food-seeking responses) and avoidance behaviors, which bring the animal closer to or further away from the food. Second, consummatory processes are triggered by contact with the food and also exist on a continuum with licking, chewing, and swallowing of ingested foods vs. distinct behaviors to reject unwanted or aversive foods (Balleine, 2005; Berridge and Kringelbach, 2015; Berthoud, 2012; Schier and Spector, 2019). While appetitive processes and their neurobiological substrates are broadly studied using associative learning processes (Pavlovian and instrumental conditioning), consummatory behaviors are often sidelined in the study of food-related processes. Affective responses, such as pleasure or liking, are thought to be an important component of consumption but rodents lack the ability to verbalize their like or dislike for a specific food. Therefore, paradigms tend to rely on overall consumption or choice to investigate preference for specific foods (Berridge, 2000). The inference often follows that an increase in intake reflects an increase in an animal's affective response to the food, (i.e. they like it more). However, intake does not only reflect the affective response to a food. For example, tests of the so-called 'anhedonia state' - a marked loss of motivation or pleasure - use sucrose preference tests to assess sensitivity to palatable sweet solutions. In this test, where the animal simply has access to sucrose and the absolute amount consumed is measured, it is inferred that a reduction in preference for palatable sucrose is indicative of a decrease in hedonic evaluation. Reduction in sucrose preference, however, is the result of multiple mechanisms not limited to palatability evaluation, but also including other internal processes (motivation, inter-individual sensitivity for sweet taste, stress) and external parameters (experimental condition such as light/dark cycle, sweet taste concentration, bottle position etc.) (Scheggi et al., 2018). The limit of this kind of approach is that it cannot tell us whether any change in animal's consumption of a solution is due to a 
change in the palatability of the food stimulus or a change in other factors such as physiological state.

Within this context, studies examining the microstructure of ingestive behaviors show that close investigation of consummatory behaviors can provide more nuanced and important information on the parameters controlling food intake, especially stimulus evaluation or palatability (Davis, 1996; Dwyer, 2012; Grill and Norgren, 1978; Johnson, 2018; Smith, 2001; Spector, 2000). As such, rather than simply assessing total intake across time, by analyzing the pattern in which this intake occurs, new insights into the psychological, behavioral, and neural processes that underpin ingestive behavior can be made.

In this review, we focus on how different physiological need states, from general hunger to specific nutrient requirements, affect the microstructure of licking behavior and how analysis of lick patterns can inform us about the current evaluation of food by animals. In addition, we outline some simple ways to implement and open access methods for recording and analyzing detailed lick microstructure parameters.

\section{ANALYSIS OF LICK MICROSTRUCTURE}

When rodents are presented with a spout or sipper that contains a solution they will drink from it in a stereotypical manner. Most of this licking behavior is rhythmic with licks occurring at a consistent rate of approximately 6-7 Hz in rats (Davis and Smith, 1992) or 8-10 Hz in mice (Dotson and Spector, 2005; Johnson et al., 2010). Initial work performed during the 1970s demonstrated that these periods of high frequency licking are interspersed with pauses that can range from 150 ms to many minutes (Corbit and Luschei, 1969; Halpern, 1977). Seminal experiments by Davis and Smith (1992) demonstrated that, in accordance with this modal frequency of 6-7 Hz, the vast majority of licks (e.g. $>90 \%$ ) are separated by interlick intervals (ILIs) that are less than $250 \mathrm{~ms}$. The distribution of these very short ILIs seems independent of palatability evaluation or motivational processes (Davis, 1996; Davis et al., 1994) and is thought dependent on the motor output generated by a central pattern generator in the hindbrain (Travers et al., 1997; Wiesenfeld et al., 1977). Changes in lick separated by less than $250 \mathrm{~ms}$ is usually interpreted as an alteration in oromotor function. Licks separated by pauses $>250$ ms are typically referred to as bursts of licks.

Davis and Smith (1992) went on to further subdivide the pauses between bursts into those that were approximately double the modal ILI (e.g. 250-500 ms) and those that were longer than this. They suggested that the former pauses - brief ILIs between 250 and $500 \mathrm{~ms}-$ were either a 'missed lick' caused by the tongue failing to make contact with a spout or were a brief interruption due to a lateral tongue protrusion or other mouth movement (Grill and Norgren, 
1978). The latter group of pauses - ILIs that were longer than $500 \mathrm{~ms}$ - was thought to reflect interruptions due to the animal terminating the licking episode and engaging in other behaviors such as ambulation or grooming.

Thus, division of the train of licks based on a certain pause criterion (i.e. $500 \mathrm{~ms}$ ) yields a series of bursts or clusters separated by the pauses between them. In turn, this provides a number of microstructure parameters including number of lick bouts, their sizes (licks within a burst or cluster), and the pauses between these trains (interburst or intercluster intervals). These parameters, as we will discuss further in the proceeding sections, can vary with internal state, palatability and external stimuli, which can provide insights into motivation and consumption beyond simply measuring the total amount of solution consumed (Figure 1).

The choice of pause criterion and whether bursts separated by brief ILIs due to missed licks should be combined into larger units (often known as clusters) has been studied and discussed, although no clear consensus has been reached. A number of studies have built on the original classifications from Davis and Smith (1992) to define the pauses between bursts and clusters using a range of criteria. Spector et al. (1998) made an in-depth study by analyzing the same dataset using a wide range of pause criteria to show how the choice of criterion interacted with the effect of sucrose concentration and food deprivation on licking microstructure. For instance, very short $(<300 \mathrm{~ms})$ or very long $(>10 \mathrm{~s})$ pause criteria resulted in a relationship between sucrose concentration and burst size that was nonlinear for high concentrations. The authors concluded that a pause criterion of $<1000$ s seemed the most appropriate, rather than $<500 \mathrm{~ms}$ as suggested by Davis and Smith (1992). This slightly more liberal criterion was favored as it captures within-burst events that likely reflect two or more missed licks on the spout. More recently, Johnson, et al. (2010) analyzed licking microstructure using pause criteria of $250-500,>500$ or $>1000 \mathrm{~ms}$ and determined that the latter was the most appropriate to observe differences in licking behaviors between different strains of mouse. This pause criterion of $>1000 \mathrm{~ms}$ (or $1 \mathrm{~s}$ ) is the most commonly used in mice studies (Dotson and Spector, 2005; Johnson, 2018; Johnson, et al., 2010; Mendez et al., 2015; Ostlund et al., 2013). Despite some variability in the pause criteria and the vocabulary used between studies (e.g. bursts, clusters, meals, bouts) all agree that licking behavior can be studied beyond overall intake, with its microstructural pattern providing information about the motivational and hedonic evaluation of the solution being consumed. Hereafter, in this review, we will use the term cluster to refer to bouts of licking separated by a pause criterion of at least $500 \mathrm{~ms}$.

Cluster size (or duration) has been shown to increase monotonically as concentration of sucrose or maltose increases (Davis and Perez, 1993; Davis and Smith, 1992; Spector, et al., 1998). On the other hand, cluster size decreases when water is adulterated with the bitter 
taste of quinine, even under conditions of water deprivation (Hsiao and Fan, 1993), or when a palatable taste is paired with lithium chloride inducing gastric malaise (Baird et al., 2005; Dwyer, 2009; Spector and St John, 1998). The size of clusters does not simply reflect overall consumption as highest consumption usually occurs at moderate concentrations for a specific tastant, following an inverted U-shaped curve. Moreover, cluster size is not affected in sham feeding paradigms, in which a gastrointestinal fistula prevents the solution reaching the digestive tract (Davis and Smith, 1992). The monotonic relationship between cluster size and palatable or aversive solutions strongly suggests that cluster size reflects the hedonic evaluation of the solution. Moreover, cluster size is also influenced by learning. For example, in flavor conditioning experiments in which a flavored solution is paired with a specific nutrient and compared to a less nutritive flavored solution (Sclafani, 2004), cluster size of the nutrientpaired flavor increases reflecting its elevated hedonic evaluation (Dwyer, 2012; Johnson, 2013; Myers and Sclafani, 2001; Myers and Sclafani, 2001). It is interesting to note that a decrease in cluster size as the meal progressed has been reported (Spector, et al., 1998), suggesting that cluster size is influenced by post-ingestive load and satiety processes. This decrease in cluster size could potentially reflect a decrease in palatability as a meal progresses (Berridge, 1991). However, this change in cluster size over time does not alter the difference in size between high and low sucrose concentrations. In summary, the size of lick clusters, can generally be used as a proxy to measure change in palatability of food across different physiological states or after learning, at least if considering short meal periods.

In contrast to the size of clusters, the total number of clusters within a session follows an inverted U-shaped curve as a function of concentration for many nutritive solutions (e.g. sucrose; (Davis and Smith, 1992; Spector, et al., 1998). Thus, cluster number often mirrors overall intake and is thought to reflect the effect of post-ingestive processes and a change in deprivation state (e.g. within-session satiety) on the initiation of drinking episodes. The link to post-ingestive processes is clearly confirmed by the increase in cluster number that is seen in sham feeding preparations (Davis and Smith, 1992; Smith, 2001). In addition, as cluster number is directly related to the number of times an animal initiates licking behavior, it has also been suggested to reflect the incentive value of food-related stimuli although this remains debated (Davis and Smith, 1992; Johnson, 2018; Ostlund, et al., 2013; Spector, 2000). Thus, in contrast to cluster size, the total number of clusters can be used as a readout of initiation of ingestive behavior and how it is affected by post-ingestive signals.

\section{EFFECT OF FOOD RESTRICTION AND HUNGER ON LICK MICROSTRUCTURE}


Food restriction and hunger increases the overall intake of palatable food in animal models (Berthoud, 2011; Berthoud, 2012). Early seminal studies by Davis that performed a coarse analysis of licking behavior (relative to the later methods he developed) showed that the number of licks in 30-s time bins was higher when rats were food-deprived than after rats had been allowed to consume a meal and sate their hunger (Davis, 1973). Twenty years later, using a more fine-grained analysis of lick microstructure, Davis and Perez (1993) examined food-deprived rats licking for different concentrations of sucrose. They showed that, in general, food deprivation had complex effects on licking microstructure depending upon the concentration of sucrose. At low concentrations of sucrose $(0.05$ to $0.2 \mathrm{M})$, food deprivation increased cluster number without affecting cluster size. For higher concentrations of sucrose $(>0.4 \mathrm{M})$, cluster size increased drastically, relative to the low concentrations, and this effect was potentiated by food deprivation. Surprisingly, the number of clusters was then lower in the food-deprived condition compared to non-deprived animals. To explain this discrepancy, the authors proposed that the longer licking bouts induced by food deprivation are compensated by a reduction in the frequency of these bouts so that similar overall intake is maintained.

These results differ somewhat from a later study in which, over a similar range of concentrations $(0.03-1.0 \mathrm{M})$, food-deprived rats exhibited a greater overall intake and number of bursts relative to ad libitum fed rats (Spector, et al., 1998). Interestingly, by testing multiple ILI criteria to define pauses between bursts of licks (from 0.3 to $100 \mathrm{~s}$ ), they found that with very long criteria (ILIs $\geq 30 \mathrm{~s}$ ) food deprivation increased cluster size whereas with a very short criterion (ILIs $\geq 300 \mathrm{~ms}$ ) food deprivation decreased cluster size. However, over a large range of criteria ( $0.3 \mathrm{~s} \geq \mathrm{ILI} \mathrm{s} \geq 10 \mathrm{~s}$ ), which include the pause duration used by Davis \& Perez (1993), they observed no effect of food deprivation on cluster size. The reason for the discrepancy between these two studies with respect to the effect of food deprivation on cluster size remains unclear but may reflect methodological differences including length of deprivation (17 h in Grill and Norgren, 1978; 23 h in Spector, et al., 1998), test duration (30 or 60 min) or choice of pause criterion.

In a study of successive negative contrast, Grigson et al. (1993) performed microstructural analysis when food-deprived and free-feeding rats were given 5-min access to either $0.1 \mathrm{M}$ or 1.0 M sucrose solution. Although they did not explicitly compare effects between deprivation conditions, visual inspection of their data strongly suggests that food deprivation increased cluster size for the high but not low concentration of sucrose without affecting number of clusters. Interestingly, they also noted effects of experience whereby non-deprived rats that had had prior experience of sucrose in the deprived state exhibited greater cluster size than naïve, free-feeding rats. 
More recently, Verharen et al. (2019) compared 60-min intake of $5 \%$ sucrose solution $(\approx 0.15 \mathrm{M})$ and lick microstructure between ad libitum fed and 24-h food-restricted rats using a very liberal pause criterion of 1 min to define lick clusters (here called "bouts"). In contrast to the previous studies, they reported that the increase in overall intake induced by food deprivation is not associated with an increase in cluster number. They, however, noted an (non-significant) increase in cluster size suggesting a potential increase in sucrose palatability induced by hunger state.

Similar to studies using rats, it was demonstrated that non-deprived mice exhibited a concentration-dependent increase in total licks, cluster number and cluster size when drinking sucrose (Mendez, et al., 2015; Ostlund, et al., 2013). Moreover, all of these parameters were increased when mice were food deprived for $18 \mathrm{~h}$, suggesting an increase in both incentive properties and palatability evaluation of sucrose when hungry (see also Johnson, et al., 2010).

Taken together, studies that have assessed change in lick microstructure induced by food deprivation have produced some converging findings. Importantly, an effect of deprivation on increasing cluster size has been observed several times. However, discrepancies in results are likely the result of a complex interaction between concentration of solutions, length or magnitude of food deprivation, as well as procedural and analytical differences.

\section{EFFECT OF WATER DEPLETION AND THIRST ON LICK MICROSTRUCTURE}

In contrast to the effect of hunger on licking patterns, only a few studies have investigated the effect of thirst. The main limitation is the technical difficulty in getting animals to lick for water in an experimental setting when they are not fluid deprived. Consequently, most studies only used water-deprived animals without any non-thirsty control group. As an aside, the waterdeprivation used by many studies that are designed to give insight into feeding behavior may be viewed as a confound. Moreover, a lot of studies also measured water intake in models of sodium depletion or repletion (see below), precluding a rigorous analysis of lick patterns only due to water intake (Canu et al., 2010; D'Aquila et al., 2019; D'Aquila et al., 2012; Galistu and D'Aquila, 2012). Despite these limitations, unsurprisingly these studies reported that waterdeprived animals exhibit a high number of licks for water and that these licks are organized into clusters. Moreover, pharmacological manipulations generally affect lick patterns for water in a similar way to what has been observed with ingestion of nutritive solutions.

The study by Verharen, et al. (2019), discussed in the above section, is a notable exception as they studied water intake in rats with and without 7-h water restriction. Water restriction was observed to increase the number of drinking bouts without affecting their size, although it should be noted that the analysis parameters used here differed from those conventionally 
used in lick microstructure studies. The use of longer pause criterion ( $1 \mathrm{~min}$ ) may dampen the effect of thirst on licking patterns during the initial licking episodes by averaging several shorter clusters of licks. The use of a long recording session (60 min) can also impact aspects of licking patterns that are influenced by satiety (Spector, et al., 1998).

\section{EFFECT OF SODIUM DEPLETION ON LICK MICROSTRUCTURE}

Sodium is the main extracellular cation and its depletion drives an immediate, unlearned preference for food and solutions containing sodium chloride and some other sodium salts (Denton, 1984; Geerling and Loewy, 2008; Richter, 1943; Wolf et al., 1974). This preference is manifested as increased intake of sodium-containing solutions, relative to water or other palatable solutions (Berridge et al., 1984).

Lick rate for sodium chloride is higher in sodium deplete rats compared to sodium replete rats during the first three minutes of a consumption test across a range of concentrations (Breslin et al., 1993). Several studies have demonstrated that increased sodium intake is associated with an increase in both the number of clusters and cluster size suggesting an increase in both the incentive value and the palatability of sodium chloride (Canu, et al., 2010; D'Aquila, et al., 2012; Tandon et al., 2012; Wirtshafter et al., 2012). Interestingly, using the taste reactivity procedure, another method of assessing stimulus palatability in which a specific tastant is delivered directly to the oral cavity via an intraoral catheter (Grill and Norgren, 1978), similar effects of sodium depletion were observed. As such, there was an increase in positive orofacial reactions (e.g. tongue protrusion, paw lick) and a decrease in aversive reactions (e.g. head shake, forelimb flail, face wipe, gape) in sodium deplete rats that received intra-oral infusion of sodium chloride (Berridge, et al., 1984).

More recently, Verharen, et al. (2019), using a long pause criterion to define episodes of licking (see above), reported a general trend towards sodium depletion increasing cluster number and cluster size. Moreover, sodium depletion also appeared to increase water intake during the same consumption test, but this later effect was only driven by an increase in the number of clusters and not cluster size. Thus, sodium depletion seems to drive an increase in general drinking behavior associated with a specific increase in the evaluation of sodium chloride that may drive foraging and consumption of salt-enriched food or drinks in response to a homeostatic drive.

\section{EFFECT OF PROTEIN RESTRICTION ON LICK MICROSTRUCTURE}


Protein is thought to be the most tightly regulated of the three macronutrients due to the importance of essential amino acids for most metabolic and physiological functions. Accordingly, when animals are placed on a diet that is low in protein, their patterns of food intake change in ways that drive animals to achieve an optimal level of dietary protein where possible (Gibson and Booth, 1986; Hill et al., 2019; Hill and Morrison, 2019; Laeger et al., 2014; Theall et al., 1984).

Our group recently showed that this shift to a low protein diet increases the preference for a distinctly-flavored solution that contains the dairy protein, casein, relative to a solution containing the carbohydrate, maltodextrin (Murphy et al., 2018). Analysis of lick microstructure showed that the increased casein preference in protein-restricted rats was associated with both an increase in cluster number and cluster size. These results suggest that for proteinrestricted rats there is an increase in the palatability of the protein-containing solution (based on the increase in cluster size), as well as either an increase in the incentive properties of this solution and/or a reduction in the inhibitory post-ingestive effects (based on the increase in cluster number). Interestingly, these differences were observed during the preference test session when both solutions were available, but not during preceding conditioning sessions when only one solution was available (Figure 2).

More recently, we reproduced these results using a paradigm in which casein- and maltodextrin-flavored solutions were presented in discrete 5-s trials (Figure 3A; (see Chiacchierini et al., 2019 for a more detailed description of the behavioral protocol)). Specifically, in this paradigm after having access to the solutions across a number of conditioning sessions, rats experienced a preference session in which both solutions were available. Importantly, however, this session began with 'forced choice' trials in which only one solution was presented at a time in a pseudorandom manner. In these 'forced choice' trials, no difference in cluster number or cluster size was seen, similar to the pattern of results during conditioning in our previous study when only one bottle was available (Figure 3B, left). These results demonstrate that, in absence of choice and a comparison between the two nutrientcontaining solutions, rats do not differ in their evaluation of each solution, which explains the similar amount of licking (Chiacchierini, et al., 2019; Murphy, et al., 2018).

In contrast, when the two solutions are presented simultaneously during 'free choice' trials, the pattern of results is dependent on protein restriction. Non-restricted rats exhibit similar cluster number and cluster size for both casein and maltodextrin, consistent with the absence of casein preference under this diet condition. It is however noticeable that, by using discrete trials, the number of clusters (but not cluster size) is directly dependent on the animal's choice during the limited availability of each sipper. For protein-restricted rats, however, an elevated cluster size for casein, relative to maltodextrin, is seen, similar to what we have previously 
observed (Figure 3B, right). Taken together, these results suggest that the protein appetite that emerges under low protein diet is driven by an increase in the palatability of proteincontaining food, at least when compared with food that does not contain protein. This association is reinforced by the significant correlation between cluster size during licking for casein and casein preference (Figure $3 \mathbf{C}$ ).

To investigate whether changes in the palatability of casein were responsible for driving the casein preference, we investigated the effect of progressive quinine adulteration of caseinflavored solution in non-restricted and protein-restricted rats (Figure 4A). Only the highest concentrations of quinine affected casein preference in both groups. Protein-restricted rats maintained a high casein preference up until $0.1 \mathrm{mM}$ quinine. Furthermore, even with higher quinine concentrations ( 0.5 and $1 \mathrm{mM}$ ), casein preference levels never went below $50 \%$, in contrast to what we observed in non-restricted rats (Figure 4B). Analysis of lick microstructure during quinine adulteration revealed complex effects (Figure 4C). Quinine adulteration did not affect the number of lick clusters for casein. When protein restricted, rats exhibited a greater number of clusters for casein than control animals, even at high quinine concentrations. These results suggest elevated motivation for casein in the protein-restricted group, concordant with their current homeostatic state. Moreover, in both groups, quinine adulteration decreased cluster size, confirming the reduced palatability of the casein solution as concentration of quinine increased, although the effect of quinine appeared greater in non-restricted rats. By contrast, the cluster size for maltodextrin is not affected in either group by the change in palatability of the casein solution. Our analysis demonstrates that casein preference in our model of protein appetite cannot be isolated from the effects of increased palatability of protein-containing solutions. Moreover, these effects on palatability are apparent in situations of choice and are resistant to food adulteration. An interesting possibility is that the current physiological state of protein restricted rats alters the perception of taste palatability beyond protein content itself but also overcomes the normally aversive effects of bitter taste. Accordingly, a similar effect is observed in sodium appetite protocols in which the taste of sodium chloride becomes palatable and rewarding when animals are sodium depleted (Berridge, et al., 1984; Cone et al., 2016; Robinson and Berridge, 2013). Together, these shifts in stimulus evaluation should allow an appropriate overall intake of protein in response to homeostatic needs.

Control of protein appetite also requires protein intake to be changed appropriately in accordance with the current physiological state (Figure 5A). In our studies, when rats became newly protein depleted, their preference for casein progressively increased across multiple tests in their new homeostatic state. An opposite result was observed when rats were shifted from protein-restricted diet to normal diet (Figure 5B). The increase in casein preference in 
protein-restricted rats was supported by an increase in both number of clusters and cluster size for casein (Figure 5C). Moreover, these animals also exhibited a decrease in cluster size for maltodextrin suggesting that, in addition to palatability of casein increasing, the perceived palatability of maltodextrin may also change to promote protein appetite in a situation of food choice. In contrast, newly protein replete rats increased the number of clusters during licking for both casein and maltodextrin. Intriguingly, cluster size during licking for casein is maintained even after protein levels are restored suggesting long-lasting changes in the palatability of casein in these animals. However, cluster size for maltodextrin is increased in the protein replete state.

Taken together, analysis of lick microstructure suggests that protein preference in our model is driven by changes in stimulus evaluation or palatability of the protein-containing solution (casein). Moreover, palatability of the alternative solution containing carbohydrate (maltodextrin) may also play a role in guiding food preference. It is especially noticeable that the difference in intake and lick microstructure only appeared during choice situations (e.g. free choice trials during preference test session) and not when only one option was available (e.g. conditioning and forced choice trials). This pattern could result from a form of negative contrast where, when the comparison is possible, the value of each option is adjusted relative to most optimal choice according to current physiological state (Berthoud, 2012; Flaherty, 1996).

\section{SUMMARY AND CONCLUSIONS}

The analysis of licking behavior and the associated microstructural analysis, presents an excellent opportunity to study controls of ingestive behavior at a nuanced level. In general, the size of defined trains of licks (e.g. bursts, clusters, bouts) is believed to reflect stimulus palatability, due to its positive correlation with hedonic evaluation. In contrast, the number of occurrences of these trains of licks is thought to be driven by a combination of a stimulus's incentive properties and - at least across long sessions - by the post-ingestive satiating effects of a consumed substance. In the present review, we have discussed how these different measures reveal changes in palatability and incentive evaluation of food depending on physiological need state. State-dependent changes in both of these parameters have been reported, but there are also complex effects of stimulus concentration and level of deprivation. In addition, procedural differences, either in experimental design or analysis, may influence the findings.

Despite providing numerous and important insights into fundamental processes governing consummatory behaviors, the analysis of licking microstructure also presents several 
limitations. The first issue is that analysis of licking behavior is highly dependent on the animal's behavior itself and its propensity to approach and consume food. Another popular way of assaying consummatory responses and stimulus palatability is the orofacial taste reactivity test. This technique, pioneered by Grill and colleagues, has yielded and continues to produce important insights into hedonic evaluation of taste stimuli (Berridge, 2000; Berridge and Grill, 1983; Grill and Norgren, 1978). Notably, behavioral results obtained using taste reactivity are in broad agreement with those that use lick microstructure to assess palatability. An advantage of lick microstructure is that it is a non-invasive method whereas taste reactivity - at least as performed traditionally - requires surgical implantation of an intraoral catheter. In addition, burst or cluster number is not available in taste reactivity experiments, which require additional behavioral tests to isolate incentive processes related to food consumption (Berridge, 2000). On the other hand, intraoral infusions allow delivery of a taste stimulus to be precisely controlled and the resulting orofacial movements and hedonic evaluation of a stimulus can be temporally linked to neurophysiological recordings (McCutcheon et al., 2012; Nishijo and Norgren, 1991; Roitman et al., 2008; Wheeler et al., 2008). An important consideration raised before by Dwyer (2012), is that there are few examples of studies in which microstructure of licking and taste reactivity have been used in parallel to compare the results of both approaches (Dwyer et al., 2017; Myers and Sclafani, 2001; Myers and Sclafani, 2001). This remains an area in which more work is needed especially considering that the two approaches differ with respect to the role of some neurobiological reward-related circuits.

A point that we have not discussed in this review is the possibility that the timing of the CPG that controls licking rate within bursts may be modulated by need states. A number of studies of lick microstructure report this parameter but although changes are sometimes observed, due to the fact that they are generally small, their functional significance has been questioned (Spector, et al., 1998). For instance, Davis and Perez (1993) reported that food deprivation reduced the initial lick rate but only from $6.9 \mathrm{~Hz}$ to $6.6 \mathrm{~Hz}$. Thus, most studies have instead tended to focus on the factors that turn the CPG on and off and in models of ingestive behavior based on microstructural analysis, changes to the CPG itself have generally been ignored. However, an area for future exploration with respect to need states might be the fine temporal structure that exists within bursts of licking, in particular how the interlick interval changes throughout ongoing bursts (Lin et al., 2013).

Another potential issue that affects many if not all studies analyzing lick microstructure is that experiments are conducted in relatively short behavioral sessions and often on food or fluiddeprived animals to elicit sufficient intake behavior. The study of 24-h intake patterns of food and fluid has contributed greatly to our understanding of ingestive behavior since these experiments became possible (Smith, 2000). To our knowledge, analysis of lick microstructure 
(rather than more gross meal patterning) has not been attempted in home cages over $24 \mathrm{~h}$ periods. However, analysis of lick patterns during $1 \mathrm{~h}$ sessions revealed effects of postingestive processes on cluster size (Spector, et al., 1998), similar to the effect of satiety on orofacial reactivity (Berridge, 1991), and suggesting potential interactions between long term changes in physiological state and the palatability of food. Given reduced cost and increased availability of systems for measuring lick patterns, the analysis of microstructural licking patterns during long time periods and across relevant physiological cycles may reveal novel, previously unidentified, insights into control of ingestive behavior.

As the ability to record licking behavior with high fidelity has become easier, there have been concurrent advances in analytical methods and conceptual insights. An exciting recent development is the emergence of open source models of science, which make adoption of new hardware cheap and accessible. Methods of recording lick patterns via either changes in capacitance, force, or infrared detectors are now available at sites such as www.openbehavior.org. In addition, graphical user interfaces (GUIs) are available that make analysis of lick data recorded on any system easy and intuitive. We have developed a simple GUI for this purpose in our lab (used to perform elements of the analysis in this paper; available at www.github.com/mccutcheonlab.com/Lick Calc-GUI/) and several others are also freely available (Raymond et al., 2018). Thus, the availability of such resources will let researchers apply methods of microstructural analysis to their experimental conditions and to their lick data from prior experiments. As a final point, much of the difficulty in assessing consistent effects across the literature arises from differences in the analytical methods used to classify bursts, clusters, or bouts of licking. In particular, the pause criterion that is chosen has a profound effect (Spector et al., 1998). The recent trend of publishing complete data sets along with journal articles will provide interested parties with the ability to analyze lick data from different laboratories using exactly the same parameters, which may resolve or reduce discrepancies between findings.

Beyond methodological considerations, a key remaining question concerns how microstructural parameters relate to subjective experience rather than just the sensory properties of food. Palatability as a term is used to reflect hedonic evaluation (e.g. pleasure or disgust) of a food and is distinct from the sensory-discriminative properties of a stimulus (Yeomans, 1998). Processes underlying palatability are also thought dissociable from incentive Pavlovian (Berridge and Kringelbach, 2015) and instrumental (Balleine, 2005; Wassum et al., 2011; Wassum et al., 2009) processes, which modulate approach/avoidance behaviors and pursuit of action. Although the highly palatable nature of many foods is often used to explain why they are overeaten in the absence of physiological need (e.g. "hedonic hunger"; Lowe and Butryn, 2007; Rossi and Stuber, 2018), it is clear that physiological need 
and the nutritional value of food has a strong influence on palatability (Smith, 2000). Accordingly, despite the variability in approaches employed to measure licking microstructure, several studies reviewed here reported that different physiological states influence licking patterns, especially cluster size. These effects are not limited to a specific food-associated taste or flavor and can also reflect the nutrient content. Although beyond the scope of the present review, recent studies showed that, in animal models of obesity such as binge eating or overconsumption of palatable food, analysis of lick microstructure has revealed important changes suggesting long lasting alterations in palatability and incentive processes, which may drive hedonic, non-homeostatic feeding (Johnson, 2018). Future studies using more precise and standardized approaches to dissect licking behavior will then bring a more detailed description of how physiological need states shape ingestive behavior under both normal and pathological conditions.

\section{ACKNOWLEDGEMENTS}

We would like to thank Michelle Murphy, Giulia Chiacchierini, and Eelke Snoeren for collecting some of the original data that were re-analyzed in this manuscript and Gonzalo Urcelay for helpful comments on the manuscript. We would also like to acknowledge the help and support from the staff of the Division of Biomedical Services, Preclinical Research Facility, University of Leicester, for technical support and the care of experimental animals.

Funding: This work was supported by the Biotechnology and Biological Sciences Research Council [grant \# BB/M007391/1 to J.E.M.], the European Commission [grant \# GA 631404 to J.E.M.], and The Leverhulme Trust [grant \# RPG-2017-417 to J.E.M.].

Data availability: Upon publication, all data analyzed in this paper will be available at the following address: http://dx.doi.org/10.25392/leicester.data.9248558. 


\section{REFERENCES}

Baird JP, St John SJ, Nguyen EA (2005), Temporal and qualitative dynamics of conditioned taste aversion processing: combined generalization testing and licking microstructure analysis. Behav Neurosci 119:983-1003.

Balleine BW (2005), Neural bases of food-seeking: affect, arousal and reward in corticostriatolimbic circuits. Physiol Behav 86:717-730.

Berridge KC (1991), Modulation of taste affect by hunger, caloric satiety, and sensory-specific satiety in the rat. Appetite 16:103-120.

Berridge KC (2000), Measuring hedonic impact in animals and infants: microstructure of affective taste reactivity patterns. Neurosci Biobehav Rev 24:173-198.

Berridge KC, Flynn FW, Schulkin J, Grill HJ (1984), Sodium depletion enhances salt palatability in rats. Behav Neurosci 98:652-660.

Berridge KC, Grill HJ (1983), Alternating ingestive and aversive consummatory responses suggest a two-dimensional analysis of palatability in rats. Behav Neurosci 97:563-573.

Berridge KC, Kringelbach ML (2015), Pleasure systems in the brain. Neuron 86:646-664.

Berthoud HR (2011), Metabolic and hedonic drives in the neural control of appetite: who is the boss? Curr Opin Neurobiol 21:888-896.

Berthoud HR (2012), The neurobiology of food intake in an obesogenic environment. Proc Nutr Soc 71:478-487.

Breslin PA, Kaplan JM, Spector AC, Zambito CM, Grill HJ (1993), Lick rate analysis of sodium taste-state combinations. Am J Physiol 264:R312-318.

Canu ME, Carta D, Murgia E, Serra G, D'Aquila PS (2010), Dopamine on D2-like receptors is involved in reward evaluation in water-deprived rats licking for $\mathrm{NaCl}$ and water. Pharmacol Biochem Behav 96:194-197.

Chiacchierini G, Naneix F, Peters KZ, Snoeren EM, McCutcheon J (2019), Protein appetite drives neural activity in the ventral tegmental area. bioRxiv:542340.

Cone JJ, Fortin SM, McHenry JA, Stuber GD, McCutcheon JE, Roitman MF (2016), Physiological state gates acquisition and expression of mesolimbic reward prediction signals. Proc Natl Acad Sci U S A 113:1943-1948.

Corbit JD, Luschei ES (1969), Invariance of the rat's rate of drinking. J Comp Physiol Psychol 69:119-125.

D'Aquila PS, Elia D, Galistu A (2019), Role of dopamine D1-like and D2-like receptors in the activation of ingestive behaviour in thirsty rats licking for water. Psychopharmacology (Berl).

D'Aquila PS, Rossi R, Rizzi A, Galistu A (2012), Possible role of dopamine D1-like and D2like receptors in behavioural activation and "contingent" reward evaluation in sodium- 
replete and sodium-depleted rats licking for $\mathrm{NaCl}$ solutions. Pharmacol Biochem Behav 101:99-106.

Davis JD (1996), Deterministic and probabilistic control of the behavior of rats ingesting liquid diets. Am J Physiol 270:R793-800.

Davis JD (1996), Microstructural analysis of the ingestive behavior of the rat ingesting polycose. Physiol Behav 60:1557-1563.

Davis JD, Perez MC (1993), Food deprivation- and palatability-induced microstructural changes in ingestive behavior. Am J Physiol 264:R97-103.

Davis JD, Smith GP (1992), Analysis of the microstructure of the rhythmic tongue movements of rats ingesting maltose and sucrose solutions. Behav Neurosci 106:217-228.

Davis JD, Smith GP, Kung TM (1994), Abdominal vagotomy alters the structure of the ingestive behavior of rats ingesting liquid diets. Behav Neurosci 108:767-779.

Denton DA (1984). The Hunger for Salt: An Anthropological, Physiological and Medical Analysis. Springer Verlag

Dotson CD, Spector AC (2005), Drinking spout orifice size affects licking behavior in inbred mice. Physiol Behav 85:655-661.

Dwyer DM (2009), Microstructural analysis of ingestive behaviour reveals no contribution of palatability to the incomplete extinction of a conditioned taste aversion. Q J Exp Psychol (Hove) 62:9-17.

Dwyer DM (2012), EPS Prize Lecture. Licking and liking: the assessment of hedonic responses in rodents. Q J Exp Psychol (Hove) 65:371-394.

Dwyer DM, Gasalla P, Bura S, Lopez M (2017), Flavors paired with internal pain or with nausea elicit divergent types of hedonic responses. Behav Neurosci 131:235-248.

Flaherty CF (1996) Incentive relativity. New York, NY, US: Cambridge University Press.

Galistu A, D'Aquila PS (2012), Effect of the dopamine D1-like receptor antagonist SCH 23390 on the microstructure of ingestive behaviour in water-deprived rats licking for water and $\mathrm{NaCl}$ solutions. Physiol Behav 105:230-233.

Geerling JC, Loewy AD (2008), Central regulation of sodium appetite. Exp Physiol 93:177209.

Gibson EL, Booth DA (1986), Acquired protein appetite in rats: dependence on a proteinspecific need state. Experientia 42:1003-1004.

Grigson PS, Spector AC, Norgren R (1993), Microstructural analysis of successive negative contrast in free-feeding and deprived rats. Physiol Behav 54:909-916.

Grill HJ, Norgren R (1978), The taste reactivity test. I. Mimetic responses to gustatory stimuli in neurologically normal rats. Brain Res 143:263-279.

Halpern BP (1977) Functional Anatomy of the Tongue and Mouth of Mammals. In: Drinking Behavior, vol. (J.A.W.M. W, J. M, eds), pp. 1-92. New York: Plenum Press. 
Hill CM, Laeger T, Dehner M, Albarado DC, Clarke B, Wanders D, Burke SJ, Collier JJ, et al. (2019), FGF21 Signals Protein Status to the Brain and Adaptively Regulates Food Choice and Metabolism. Cell Rep 27:2934-2947 e2933.

Hill CM, Morrison CD (2019), The Protein Leverage Hypothesis: A 2019 Update for Obesity. Obesity (Silver Spring) 27:1221.

Hsiao S, Fan RJ (1993), Additivity of taste-specific effects of sucrose and quinine: microstructural analysis of ingestive behavior in rats. Behav Neurosci 107:317-326.

Johnson AW (2013), Eating beyond metabolic need: how environmental cues influence feeding behavior. Trends Neurosci 36:101-109.

Johnson AW (2018), Characterizing ingestive behavior through licking microstructure: Underlying neurobiology and its use in the study of obesity in animal models. Int J Dev Neurosci 64:38-47.

Johnson AW, Sherwood A, Smith DR, Wosiski-Kuhn M, Gallagher M, Holland PC (2010), An analysis of licking microstructure in three strains of mice. Appetite 54:320-330.

Laeger T, Henagan TM, Albarado DC, Redman LM, Bray GA, Noland RC, Munzberg H, Hutson SM, et al. (2014), FGF21 is an endocrine signal of protein restriction. J Clin Invest 124:3913-3922.

Lin XB, Pierce DR, Light KE, Hayar A (2013), The fine temporal structure of the rat licking pattern: what causes the variabiliy in the interlick intervals and how is it affected by the drinking solution? Chem Senses 38:685-704.

Lowe MR, Butryn ML (2007), Hedonic hunger: a new dimension of appetite? Physiol Behav 91:432-439.

McCutcheon JE, Ebner SR, Loriaux AL, Roitman MF (2012), Encoding of aversion by dopamine and the nucleus accumbens. Front Neurosci 6:137.

Mendez IA, Ostlund SB, Maidment NT, Murphy NP (2015), Involvement of Endogenous Enkephalins and beta-Endorphin in Feeding and Diet-Induced Obesity. Neuropsychopharmacology 40:2103-2112.

Murphy M, Peters KZ, Denton BS, Lee KA, Chadchankar H, McCutcheon JE (2018), Restriction of dietary protein leads to conditioned protein preference and elevated palatability of protein-containing food in rats. Physiol Behav 184:235-241.

Myers KP, Sclafani A (2001), Conditioned enhancement of flavor evaluation reinforced by intragastric glucose. II. Taste reactivity analysis. Physiol Behav 74:495-505.

Myers KP, Sclafani A (2001), Conditioned enhancement of flavor evaluation reinforced by intragastric glucose: I. Intake acceptance and preference analysis. Physiol Behav 74:481493.

Nishijo H, Norgren R (1991), Parabrachial gustatory neural activity during licking by rats. J Neurophysiol 66:974-985. 
Ostlund SB, Kosheleff A, Maidment NT, Murphy NP (2013), Decreased consumption of sweet fluids in mu opioid receptor knockout mice: a microstructural analysis of licking behavior. Psychopharmacology (Berl) 229:105-113.

Raymond MA, Mast TG, Breza JM (2018), An open-source lickometer and microstructure analysis program. HardwareX 4.

Richter CP (1943), Total self regulatory functions in animals and human beings. Harvey Lecture Series 38:63-103.

Robinson MJ, Berridge KC (2013), Instant transformation of learned repulsion into motivational "wanting". Curr Biol 23:282-289.

Roitman MF, Wheeler RA, Wightman RM, Carelli RM (2008), Real-time chemical responses in the nucleus accumbens differentiate rewarding and aversive stimuli. Nat Neurosci 11:1376-1377.

Rossi MA, Stuber GD (2018), Overlapping Brain Circuits for Homeostatic and Hedonic Feeding. Cell Metab 27:42-56.

Scheggi S, De Montis MG, Gambarana C (2018), Making Sense of Rodent Models of Anhedonia. Int J Neuropsychopharmacol 21:1049-1065.

Schier LA, Spector AC (2019), The Functional and Neurobiological Properties of Bad Taste. Physiol Rev 99:605-663.

Schwartz MW, Woods SC, Porte D, Jr., Seeley RJ, Baskin DG (2000), Central nervous system control of food intake. Nature 404:661-671.

Sclafani A (2004), Oral and postoral determinants of food reward. Physiol Behav 81:773-779.

Smith GP (2000), The controls of eating: a shift from nutritional homeostasis to behavioral neuroscience. Nutrition 16:814-820.

Smith GP (2001), John Davis and the meanings of licking. Appetite 36:84-92.

Spector AC (2000), Linking gustatory neurobiology to behavior in vertebrates. Neurosci Biobehav Rev 24:391-416.

Spector AC, Klumpp PA, Kaplan JM (1998), Analytical issues in the evaluation of food deprivation and sucrose concentration effects on the microstructure of licking behavior in the rat. Behav Neurosci 112:678-694.

Spector AC, St John SJ (1998), Role of taste in the microstructure of quinine ingestion by rats. Am J Physiol 274:R1687-1703.

Tandon S, Simon SA, Nicolelis MA (2012), Appetitive changes during salt deprivation are paralleled by widespread neuronal adaptations in nucleus accumbens, lateral hypothalamus, and central amygdala. J Neurophysiol 108:1089-1105.

Theall CL, Wurtman JJ, Wurtman RJ (1984), Self-selection and regulation of protein: carbohydrate ratio in foods adult rats eat. J Nutr 114:711-718. 
Travers JB, Dinardo LA, Karimnamazi H (1997), Motor and premotor mechanisms of licking. Neurosci Biobehav Rev 21:631-647.

Verharen JPH, Roelofs TJM, Menting-Henry S, Luijendijk MCM, Vanderschuren L, Adan RAH (2019), Limbic control over the homeostatic need for sodium. Sci Rep 9:1050.

Volkow ND, Wang GJ, Baler RD (2011), Reward, dopamine and the control of food intake: implications for obesity. Trends Cogn Sci 15:37-46.

Wassum KM, Ostlund SB, Balleine BW, Maidment NT (2011), Differential dependence of Pavlovian incentive motivation and instrumental incentive learning processes on dopamine signaling. Learn Mem 18:475-483.

Wassum KM, Ostlund SB, Maidment NT, Balleine BW (2009), Distinct opioid circuits determine the palatability and the desirability of rewarding events. Proc Natl Acad Sci U S A 106:12512-12517.

Wheeler RA, Twining RC, Jones JL, Slater JM, Grigson PS, Carelli RM (2008), Behavioral and electrophysiological indices of negative affect predict cocaine self-administration. Neuron 57:774-785.

Wiesenfeld Z, Halpern BP, Tapper DN (1977), Licking behavior: evidence of hypoglossal oscillator. Science 196:1122-1124.

Wirtshafter D, Covelo IR, Salija I, Stratford TR (2012), Effects of muscimol in the nucleus accumbens shell on salt appetite and sucrose intake: a microstructural study with a comment on the sensitization of salt intake. Behav Neurosci 126:699-709.

Wolf G, McGovern JF, Dicara LV (1974), Sodium appetite: some conceptual and methodologic aspects of a model drive system. Behav Biol 10:27-42.

Yeomans MR (1998), Taste, palatability and the control of appetite. Proc Nutr Soc 57:609615. 


\section{CAPTIONS}

Figure 1. Analysis of lick microstructure. (A) Schematic showing division of lick train into clusters. Vertical lines show licks and horizontal lines show the first interlick interval and all intercluster intervals (see main text for additional details on lick clusters). The first lick in each cluster is shown in red. A 'missed' lick is shown as a dotted grey line and indicated with an arrow. (B) Excerpt of data from a male Sprague Dawley rat licking for $0.2 \%$ sodium saccharin. Licks are shown by vertical lines with the first lick in each cluster shown in red. Data are approximately $30 \mathrm{~s}$ taken from a $1 \mathrm{~h}$ behavioral session. (C) Histogram of interlick intervals shown for the session in B. The rhythmicity of most licking behavior is shown as the majority of interlick intervals fall within a narrow range (e.g. 0.1-0.5 s). (D) Cumulative probability distribution of burst sizes from the behavioral session shown in $\mathrm{B}$.

Figure 2. Analysis of lick microstructure in protein-restricted rats shows that changes in lick patterns are dependent on experiencing both protein and carbohydrate together. (A) Number of clusters for casein (protein) and maltodextrin (carbohydrate) does not differ for protein-restricted $(P R)$ or control, non-restricted $(N R)$ rats in conditioning sessions in which only one nutrient is available at any time (left and center panels). However, in the preference test session when both solutions are available at the same time (right panel), protein restricted rats produce more clusters for casein, relative to maltodextrin (2-way ANOVA: Diet $x$ Solution interaction [F1,22=7.119, $p=0.014]$; Sidak's post hoc test: $N R p=0.9, P R p=0.003$ ). (B) $A$ similar pattern of results is seen for cluster size in which no differences are seen when nutrients are presented on their own but in the preference test session, protein-restricted rats exhibit greater cluster size for casein than for maltodextrin (2-way ANOVA: Diet $x$ Solution interaction [F1,22=7.009, $p=0.014]$; Sidak's post hoc test: $N R p=0.8, P R p=0.009)$. Circles are data from individual rats and bars are mean. Results of this study have previously been published in Murphy et al. (2018). †† $p<0.01$ (2-way ANOVA followed by Sidak's post hoc tests casein vs. maltodextrin).

Figure 3. Protein preference is associated with specific lick patterns only during the expression of protein preference. (A) Schematic representation of the behavioral protocol. Non-restricted (NR, $n=13$; grey and white bars) and protein-restricted (PR, $n=11$; orange bars) rats initially received separate conditioning sessions for two different solutions containing casein (protein) or maltodextrin (carbohydrate). During the preference test, they experienced forced choice trials (only one bottle is presented for $30 \mathrm{~s}$ maximum or $5 \mathrm{~s}$ after the first lick), followed by free choice trials ( 2 bottles presented). (B) Analysis of lick microstructure during 
forced and free choice trials for casein and maltodextrin drinking. During forced choice trials (left panels), NR and PR groups did not present any difference of either cluster size (2-way ANOVA: Diet $\left[\mathrm{F}_{1,22}=0.3, \mathrm{p}=0.6\right]$; Solution $\left[\mathrm{F}_{1,22}=0.5, \mathrm{p}=0.5\right]$; Diet $\mathrm{x}$ Solution interaction $\left[F_{1,22}=0.2, p=0.7\right]$ ) or the number of clusters (Diet $\left[F_{1,22}=0.4, p=0.5\right]$; Solution $\left[F_{1,22}=0.05\right.$, $p=0.8]$; Diet $x$ Solution interaction $\left[F_{1,22}=1.6, p=0.2\right]$ ) for either solution. During free choice trials (right panels), PR rats presented a higher cluster size for casein than for maltodextrin (2-way ANOVA: Diet $x$ Solution interaction $\left[F_{1,22}=16.47, p=0.0005\right]$; Sidak's post hoc test $p=0.002$ ) and higher number of clusters for casein (Diet $x$ Solution interaction $\left[F_{1,22}=18.11, p=0.0003\right.$ ]; Sidak's post hoc test $\mathrm{p}=0.025)$. NR rats only presented a higher number of clusters for maltodextrin (Sidak's post hoc test $\mathrm{p}=0.006$ ) but similar cluster size for both solutions (Sidak's post hoc test $\mathrm{p}=0.14)$. (C) During free choice trials, PR rats presented a significantly higher preference for casein (left; unpaired t-test: $t_{22}=5.16, p<0.0001$; one-sample $t$-test versus $50 \%$ : $\mathrm{p}=0.003$ ). In contrast, NR rats exhibited a preference for maltodextrin (one-sample t-test versus 50\%: $p=0.005$ ). Correlation analyses (right) showed that cluster size for casein and maltodextrin are both correlated with the level of casein preference (Pearson correlations; casein: $r^{2}=0.22, p=0.02$ / maltodextrin: $r^{2}=0.60, p<0.0001$ ). Circles are data from individual rats and bars are mean. ${ }^{* * *}$ Diet effect (unpaired t-test), \# $p<0.01$ (one sample t-test versus 50\%), $\dagger p<0.05$ and $\dagger \dagger p<0.01$ (2-way ANOVA followed by Sidak's post hoc tests casein vs. maltodextrin).

Figure 4. Protein appetite is linked to increased palatability of casein, which is resistant to adulteration with quinine. (A) Schematic representation of the quinine adulteration experimental design. After initial flavor conditioning, preference for casein vs. maltodextrin was tested with increasing concentrations of quinine (from 0 to $1 \mathrm{mM}$ ) in the casein solution for both non-restricted (NR, $n=4$; grey and white symbols) and protein-restricted rats ( $P R, n=4$; orange symbols). Each quinine concentration was tested twice and averaged. (B) Casein preference progressively decreased as quinine concentration increased (2-way ANOVA: Diet $\left[F_{1,6}=9.6, p=0.02\right]$; Quinine $\left[F_{5,30}=4.5, p=0.004\right]$; Diet $x$ Quinine interaction $\left[F_{5,30}=9.6, p=0.8\right]$ ). In NR rats, the increase of quinine concentration progressively drove the preference from no preference ( $0 \mathrm{mM}$ : $\mathrm{p}=1.0$, one-sample t-test versus $50 \%)$ to maltodextrin preference $(0.5 \mathrm{mM}$ : $p=0.09 ; 1 \mathrm{mM}: p=0.01)$. In PR rats, only the highest concentrations of quinine decreased the initial casein preference to no preference without reducing preference to less than $50 \%(0.5$ $\mathrm{mM}: p=0.6 ; 1 \mathrm{mM}: p=0.7$ ). (C) Analysis of lick microstructure during quinine adulteration of casein. Left: Quinine adulteration significantly decreased cluster size during licking for casein for both groups (2-way ANOVA: Diet [ $F_{1,6}=4.2, p=0.08$ ]; Quinine $\left[F_{5,30}=28.5, p<0.0001\right]$; Diet $x$ Quinine interaction $\left[F_{5,30}=2.1, p=0.08\right]$ ), especially at high concentrations (Dunnett's post hoc 
tests versus $0 \mathrm{mM}$; NR: $p<0.001$ and $p<0.001$ for $0.5 \mathrm{mM}$ and $1 \mathrm{mM}$ respectively / PR: $p=0.005$ and $\mathrm{p}=0.04$ for $0.5 \mathrm{mM}$ and $1 \mathrm{mM}$, respectively). In contrast, cluster size for maltodextrin was not affected (2-way ANOVA: all effects Fs<1.5, p>0.2). Right: Quinine adulteration did not decrease the number of clusters during licking for casein (2-way ANOVA: Diet $\left[F_{1,6}=15.3\right.$, $p=0.008]$; Quinine $\left[F_{5,30}=1.5, p=0.2\right]$; Diet $x$ Quinine interaction $\left[F_{5,30}=0.8, p=0.6\right]$ ) but increased the number of clusters for maltodextrin (2-way ANOVA: Diet $\left[F_{1,6}=10.4, p=0.02\right]$; Quinine $\left[F_{5,30}=4.7, p=0.003\right]$; Diet $x$ Quinine interaction $\left.\left[F_{5,30}=0.7, p=0.6\right]\right)$. Data are expressed as mean + SEM. \# $p<0.05, \#$, $<<0.01$ (one sample t-test versus 50\%).

Figure 5. Change in protein appetite is related to change in lick microstructure for both casein (protein) and maltodextrin. (A) Schematic representation of the diet switch experimental design. Preference for casein vs. maltodextrin was tested after initial flavor conditioning sessions (test 1 ). Diet was then reversed between the two groups. Casein preference was tested after 1 week under the new diet (test 2) and again after new conditioning sessions (test 3). (B) Casein preference changes according to the current diet (2-way ANOVA: Diet $x$ Test interaction $\left.\left[F_{2,28}=12.6, p=0.0001\right]\right)$. The shift from non-restricted $(N R, n=9)$ to protein-restricted $(P R, n=7)$ state especially increased casein preference (Dunnett's post hoc test, test 1 vs. $2 p=0.006$, test 1 vs. $3 p=0.01$ ), abolishing the initial difference between diet groups (NR vs. PR: test $1 p=0.005$, test $2 p=0.9$, test $3 p=0.6$; Sidak's post hoc test). (C) Analysis of lick microstructure before and after the diet switch in NR and PR rats. Left: The change from NR to PR increased cluster size during casein licking, whereas the opposite diet shift (PR to NR) slightly decreased these measures (2-way ANOVA: Diet x Test interaction $\left.\left[F_{2,28}=3.4, p=0.0458\right]\right)$. Simultaneously, the $N R$ to $P R$ shift significantly decreased cluster size for maltodextrin (2-way ANOVA: Diet $x$ Test interaction $\left[F_{2,28}=8.0, p=0.0017\right]$; Dunnett's post hoc test, test 1 vs. $2 p=0.007$, test 1 vs. $3 p=0.01$ ). In contrast, the PR to NR shift did not significantly change cluster size for maltodextrin (Dunnett's post hoc test, test 1 vs. $2 p=0.15$, test 1 vs. $3 p=0.36)$. Right: Diet shift increased number of clusters for casein in both groups (2-way ANOVA: Test $\left[F_{1,14}=7.3, p=0.003\right]$, Diet $x$ Test interaction $\left[F_{2,28}=0.8, p=0.42\right]$. However, the number of clusters for maltodextrin non-significantly increased (PR to NR) or decreased (NR to PR) with diet switch (2-way ANOVA: Diet $x$ Test interaction $\left[F_{2,28}=4.3, p=0.02\right]$; all Dunnett's post hoc $p>0.06$ ). Data are expressed as mean $+\mathrm{SEM}$. \# $p<0.05$ (one sample t-test versus $50 \%$ ), $† p<0.05$ and $\dagger+p<0.01$ (2-way ANOVA followed by Dunnett's post hoc tests versus preference test 1 ), ${ }^{*} p<0.05$ (2-way ANOVA followed by Sidak's post hoc tests NR vs. PR). 


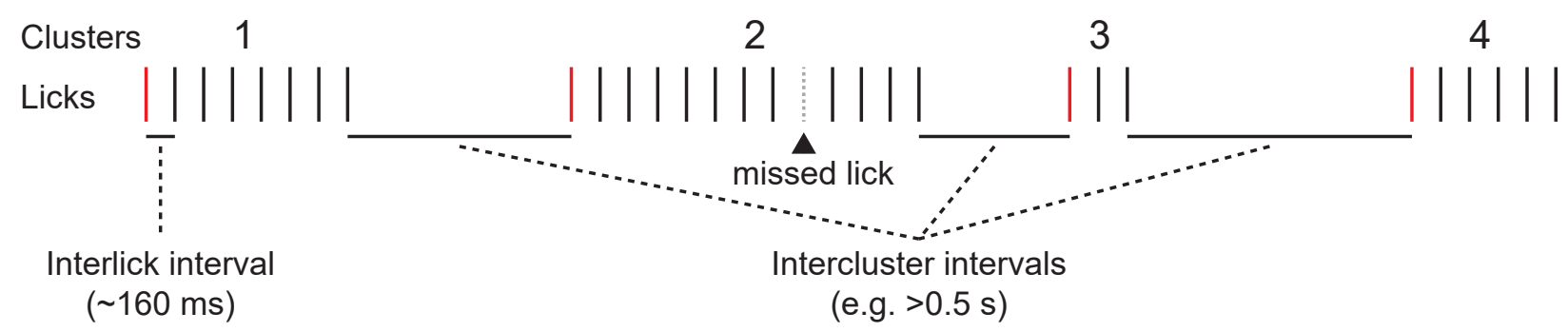

B

\begin{tabular}{|c|c|c|c|c|c|c|}
\hline Licks & 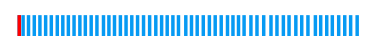 & 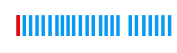 & 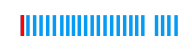 & & 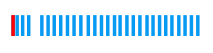 & |||||||I| \\
\hline & 5 & 10 & 15 & 20 & 25 & 30 \\
\hline
\end{tabular}

C

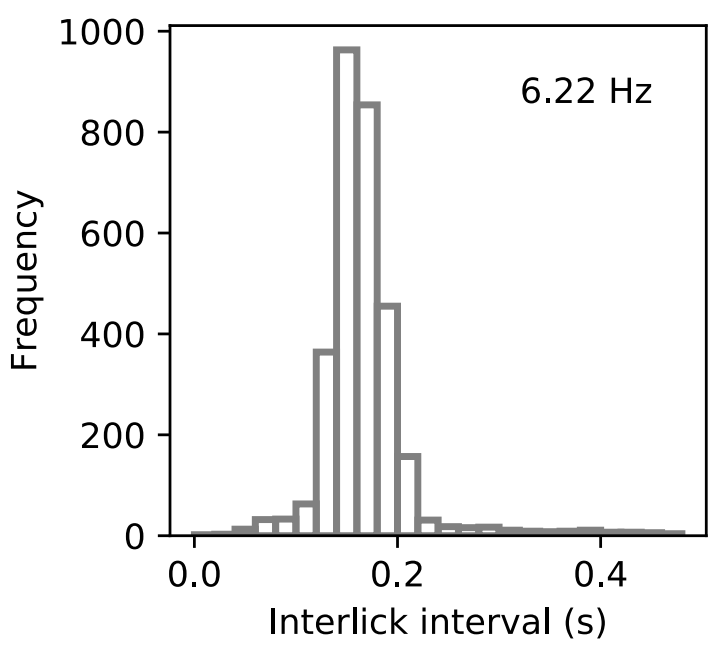

D

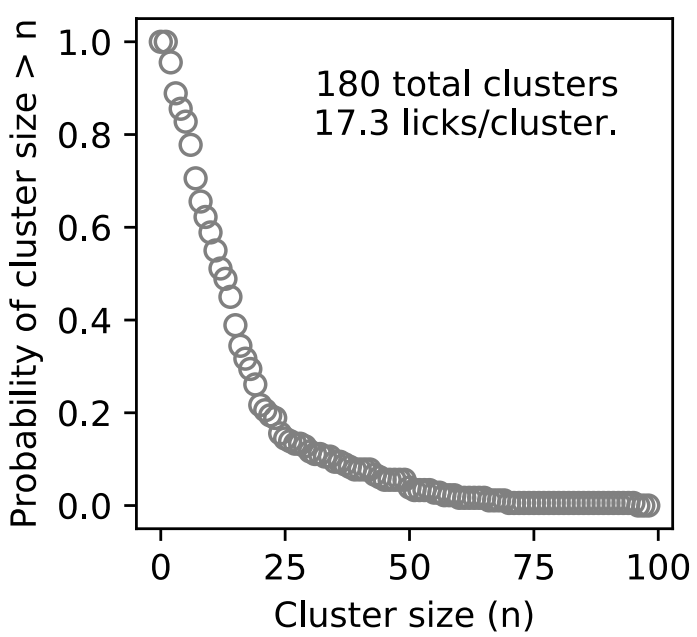

Figure 1. Analysis of lick microstructure. (A) Schematic showing division of lick train into clusters. Vertical lines show licks and horizontal lines show the first interlick interval and all intercluster intervals (see main text for additional details on lick clusters). The first lick in each cluster is shown in red. A 'missed' lick is shown as a dotted grey line and indicated with an arrow. (B) Excerpt of data from a male Sprague Dawley rat licking for $0.2 \%$ sodium saccharin. Licks are shown by vertical lines with the first lick in each cluster shown in red. Data are approximately $30 \mathrm{~s}$ taken from a $1 \mathrm{~h}$ behavioral session. (C) Histogram of interlick intervals shown for the session in B. The rhythmicity of most licking behavior is shown as the majority of interlick intervals fall within a narrow range (e.g. 0.1-0.5 s). (D) Cumulative probability distribution of burst sizes from the behavioral session shown in B. 

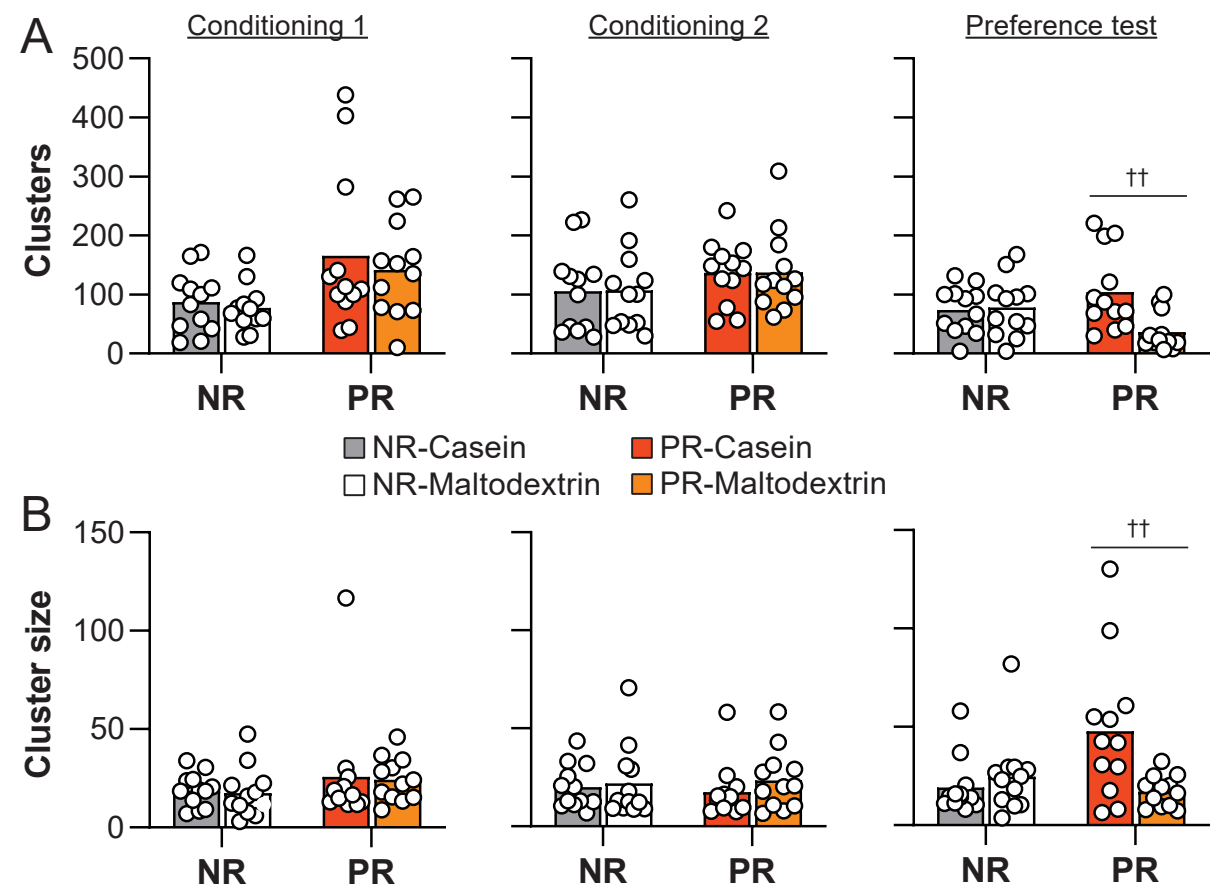

Figure 2. Analysis of lick microstructure in protein-restricted rats shows that changes in lick patterns are dependent on experiencing both protein and carbohydrate together. (A) Number of clusters for casein (protein) and maltodextrin (carbohydrate) does not differ for protein-restricted (PR) or control, non-restricted (NR) rats in conditioning sessions in which only one nutrient is available at any time (left and center panels). However, in the preference test session when both solutions are available at the same time (right panel), protein restricted rats produce more clusters for casein, relative to maltodextrin (2-way ANOVA: Diet $x$ Solution interaction $[F 1,22=7.119, p=0.014]$; Sidak's post hoc test: $N R p=0.9, P R p=0.003$ ). (B) A similar pattern of results is seen for cluster size in which no differences are seen when nutrients are presented on their own but in the preference test session, protein-restricted rats exhibit greater cluster size for casein than for maltodextrin (2-way ANOVA: Diet $x$ Solution interaction [F1,22=7.009, $p=0.014]$; Sidak's post hoc test: NR $p=0.8, P R p=0.009$ ). Circles are data from individual rats and bars are mean. Results of this study have previously been published in Murphy et al. (2018). †† $p<0.01$ (2-way ANOVA followed by Sidak's post hoc tests casein vs. maltodextrin). 

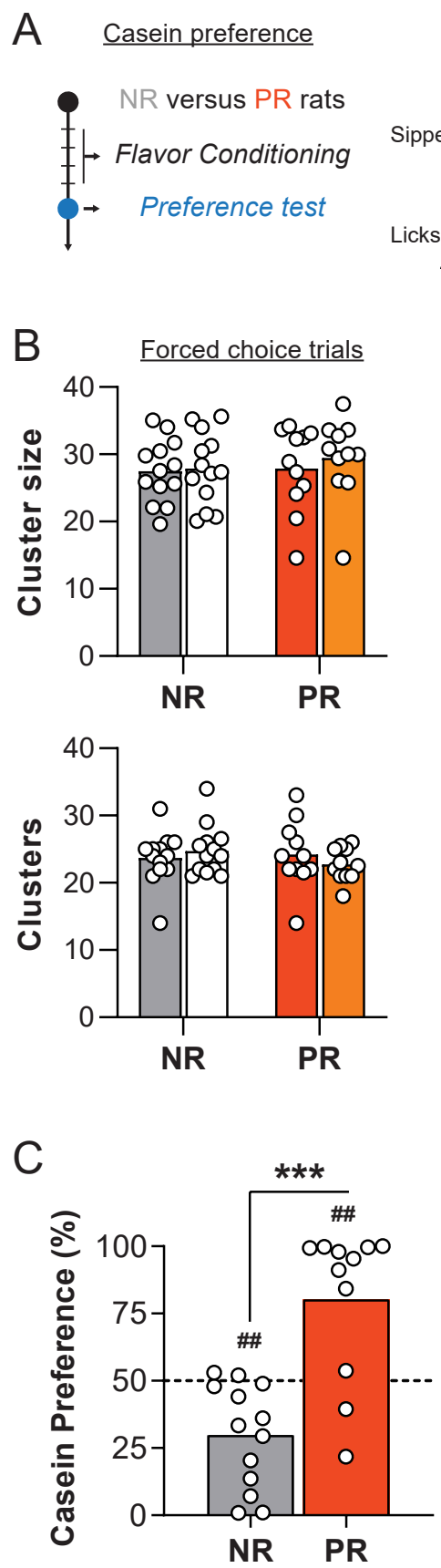

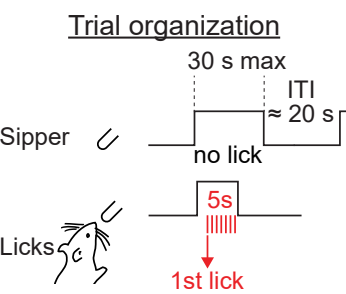

Free choice trials

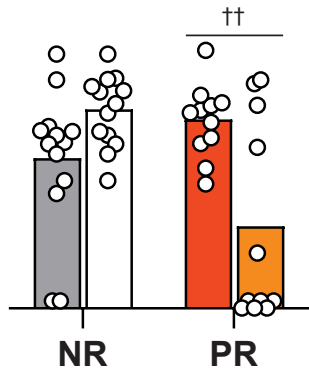

$\square$ NR-Casein

$\square$ NR-Maltodextrin

$\square$ PR-Casein

$\square$ PR-Maltodextrin

Conditioning \&

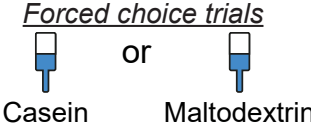

Free choice trials

$\bigoplus_{\text {Casein }}$ vs.

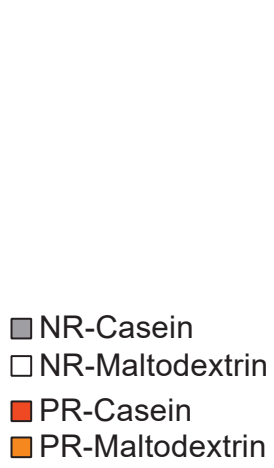

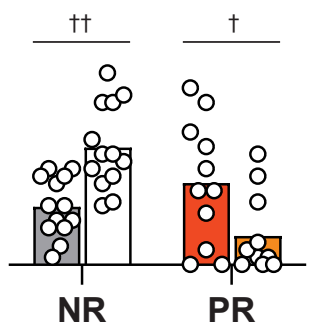

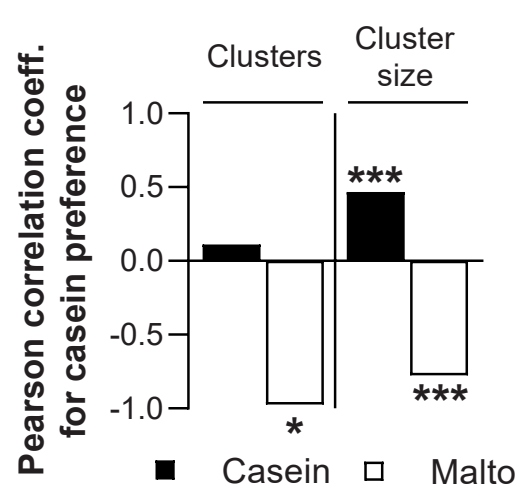

Figure 3. Protein preference is associated with specific lick patterns only during the expression of protein preference. $(A)$ Schematic representation of the behavioral protocol. Non-restricted $(N R, n=13$; grey and white bars) and protein-restricted ( $P R, n=11$; orange bars) rats initially received separate conditioning sessions for two different solutions containing casein (protein) or maltodextrin (carbohydrate). During the preference test, they experienced forced choice trials (only one bottle is presented for $30 \mathrm{~s}$ maximum or $5 \mathrm{~s}$ after the first lick), followed by free choice trials ( 2 bottles presented). (B) Analysis of lick microstructure during forced and free choice trials for casein and maltodextrin drinking. During forced choice trials (left panels), NR and PR groups did not present any difference of either cluster size (2-way ANOVA: Diet $[F 1,22=0.3, p=0.6]$; Solution $[F 1,22=0.5, p=0.5]$; Diet $x$ Solution interaction $[F 1,22=0.2$, $p=0.7]$ ) or the number of clusters (Diet $[F 1,22=0.4, p=0.5]$; Solution $[F 1,22=0.05, p=0.8]$; Diet $x$ Solution interaction $[F 1,22=1.6, p=0.2]$ ) for either solution. During free choice trials (right panels), PR rats presented a higher cluster size for casein than for maltodextrin (2-way ANOVA: Diet $x$ Solution interaction $[F 1,22=16.47, p=0.0005]$; Sidak's post hoc test $p=0.002$ ) and higher number of clusters for casein (Diet $x$ Solution interaction $[F 1,22=18.11, p=0.0003]$; Sidak's post hoc test $p=0.025)$. NR rats only presented a higher number of clusters for maltodextrin (Sidak's post hoc test $p=0.006$ ) but similar cluster size for both solutions (Sidak's post hoc test $p=0.14$ ). (C) During free choice trials, PR rats presented a significantly higher preference for casein (left; unpaired t-test: t22 $=5.16, p<0.0001$; one-sample t-test versus $50 \%$ : $\mathrm{p}=0.003$ ). In contrast, NR rats exhibited a preference for maltodextrin (one-sample t-test versus $50 \%$ : $\mathrm{p}=0.005$ ). Correlation analyses (right) showed that cluster size for casein and maltodextrin are both correlated with the level of casein preference (Pearson correlations; casein: $r 2=0.22, p=0.02$ / maltodextrin: $\mathrm{r} 2=0.60, \mathrm{p}<0.0001)$. Circles are data from individual rats and bars are mean. ${ }^{* *}$ Diet effect (unpaired t-test), \#\# $p<0.01$ (one sample t-test versus 50\%), $\uparrow p<0.05$ and $\dagger \dagger p<0.01$ (2-way ANOVA followed by Sidak's post hoc tests casein vs. maltodextrin). 
A Casein preference and quinine adulteration

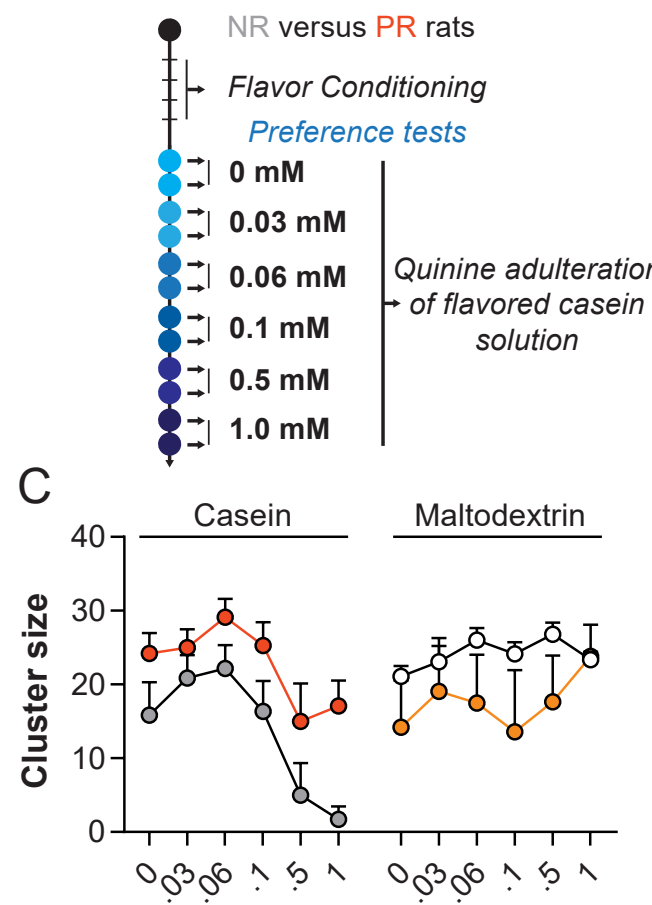

[Quinine] (in mM)
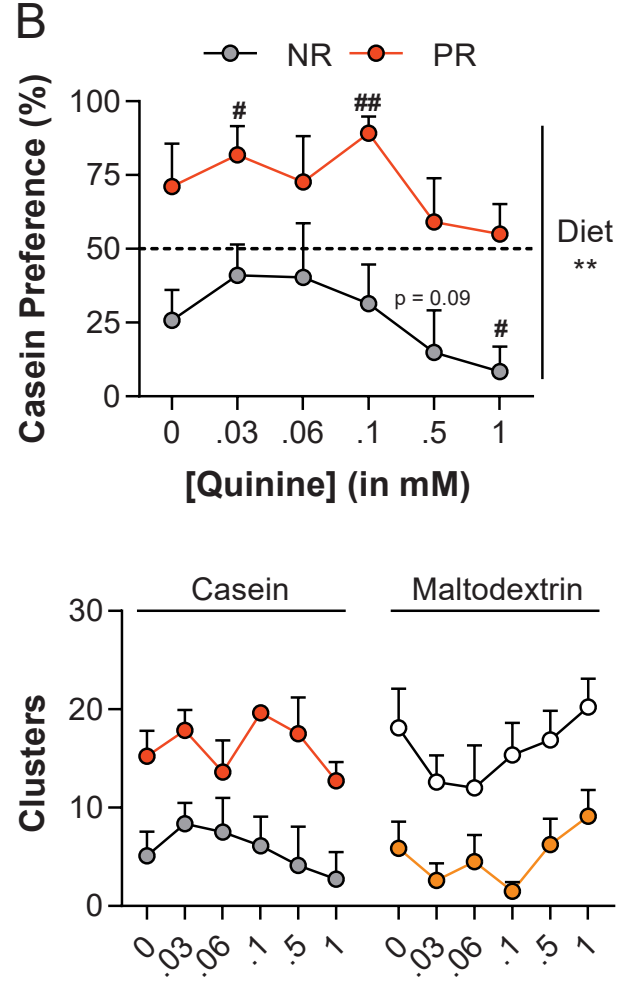

[Quinine] (in $\mathrm{mM}$ )

$\square \square$ NR $\square \square P R$

Figure 4. Protein appetite is linked to increased palatability of casein, which is resistant to adulteration with quinine. (A) Schematic representation of the quinine adulteration experimental design. After initial flavor conditioning, preference for casein vs. maltodextrin was tested with increasing concentrations of quinine (from 0 to $1 \mathrm{mM}$ ) in the casein solution for both non-restricted (NR, $\mathrm{n}=4$; grey and white symbols) and protein-restricted rats ( $P R, n=4$; orange symbols). Each quinine concentration was tested twice and averaged. (B) Casein preference progressively decreased as quinine concentration increased (2-way ANOVA: Diet [F1,6=9.6, $p=0.02]$; Quinine [F5,30=4.5, $p=0.004]$; Diet $x$ Quinine interaction $[F 5,30=9.6, p=0.8]$ ). In NR rats, the increase of quinine concentration progressively drove the preference from no preference $(0 \mathrm{mM}: p=1.0$, one-sample t-test versus $50 \%)$ to maltodextrin preference $(0.5 \mathrm{mM}: p=0.09 ; 1 \mathrm{mM}: p=0.01)$. In PR rats, only the highest concentrations of quinine decreased the initial casein preference to no preference without reducing preference to less than $50 \%(0.5 \mathrm{mM}: p=0.6 ; 1 \mathrm{mM}: p=0.7)$. (C) Analysis of lick microstructure during quinine adulteration of casein. Left: Quinine adulteration significantly decreased cluster size during licking for casein for both groups (2-way ANOVA: Diet [F1,6=4.2, $p=0.08]$; Quinine [F5,30=28.5, $p<0.0001]$; Diet $x$ Quinine interaction [F5,30 $=2.1, p=0.08]$ ), especially at high concentrations (Dunnett's post hoc tests versus 0 $\mathrm{mM}$; NR: $p<0.001$ and $p<0.001$ for $0.5 \mathrm{mM}$ and $1 \mathrm{mM}$ respectively / PR: $p=0.005$ and $p=0.04$ for $0.5 \mathrm{mM}$ and $1 \mathrm{mM}$, respectively). In contrast, cluster size for maltodextrin was not affected (2-way ANOVA: all effects Fs<1.5, $p>0.2)$. Right: Quinine adulteration did not decrease the number of clusters during licking for casein (2-way ANOVA: Diet [F1,6=15.3, $p=0.008]$; Quinine $[F 5,30=1.5, p=0.2]$; Diet $x$ Quinine interaction $[F 5,30=0.8$, $p=0.6]$ ) but increased the number of clusters for maltodextrin (2-way ANOVA: Diet $[F 1,6=10.4, p=0.02]$; Quinine $[F 5,30=4.7, p=0.003]$; Diet $x$ Quinine interaction $[F 5,30=0.7, p=0.6]$ ). Data are expressed as mean + SEM. \# $p<0.05, \# \# p<0.01$ (one sample t-test versus $50 \%$ ). 
A

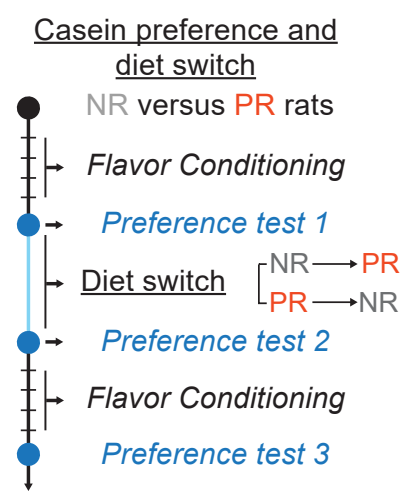

C

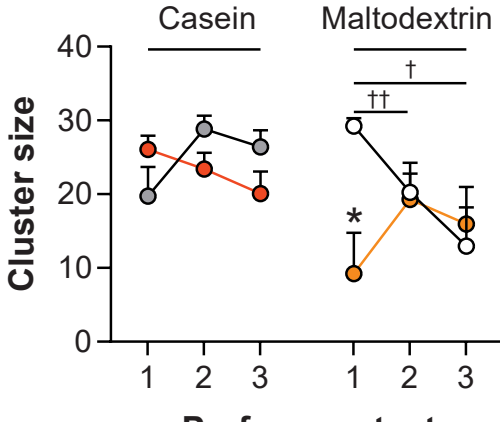

Preference test
B
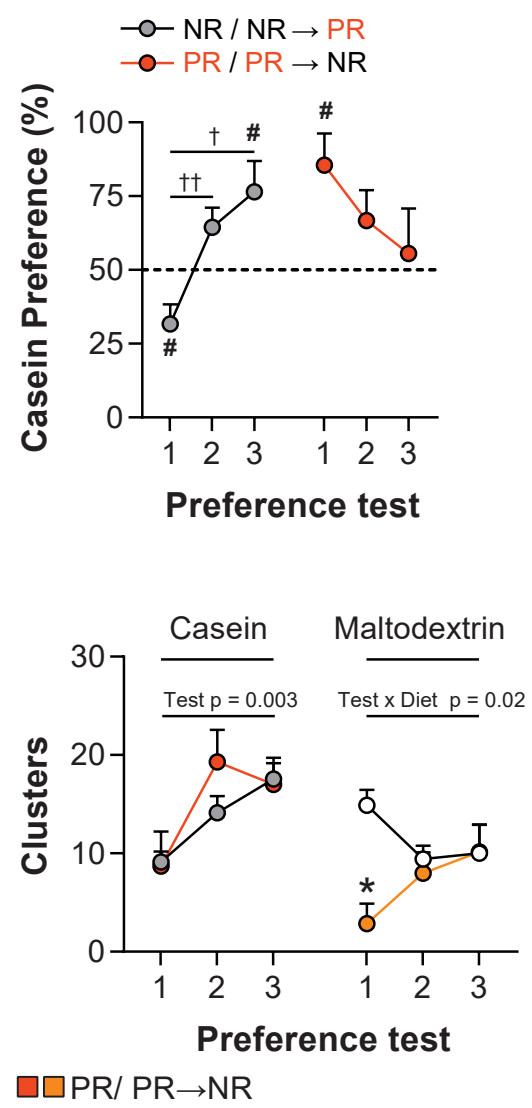

Figure 5. Change in protein appetite is related to change in lick microstructure for both casein (protein) and maltodextrin. (A) Schematic representation of the diet switch experimental design. Preference for casein vs. maltodextrin was tested after initial flavor conditioning sessions (test 1). Diet was then reversed between the two groups. Casein preference was tested after 1 week under the new diet (test 2) and again after new conditioning sessions (test 3 ). (B) Casein preference changes according to the current diet (2-way ANOVA: Diet $x$ Test interaction $[F 2,28=12.6, p=0.0001])$. The shift from non-restricted $(N R, n=9)$ to protein-restricted $(P R, n=7)$ state especially increased casein preference (Dunnett's post hoc test, test 1 vs. $2 p=0.006$, test 1 vs. $3 p=0.01$ ), abolishing the initial difference between diet groups (NR vs. PR: test $1 p=0.005$, test $2 p=0.9$, test 3 $p=0.6$; Sidak's post hoc test). (C) Analysis of lick microstructure before and after the diet switch in NR and PR rats. Left: The change from NR to PR increased cluster size during casein licking, whereas the opposite diet shift (PR to NR) slightly decreased these measures (2-way ANOVA: Diet $x$ Test interaction [F2,28=3.4, $p=0.0458]$ ). Simultaneously, the NR to PR shift significantly decreased cluster size for maltodextrin (2-way ANOVA: Diet $x$ Test interaction [F2,28=8.0, $p=0.0017]$; Dunnett's post hoc test, test 1 vs. $2 p=0.007$, test 1 vs. $3 p=0.01$ ). In contrast, the PR to NR shift did not significantly change cluster size for maltodextrin (Dunnett's post hoc test, test 1 vs. $2 p=0.15$, test 1 vs. $3 p=0.36$ ). Right: Diet shift increased number of clusters for casein in both groups (2-way ANOVA: Test [F1,14=7.3, $p=0.003]$, Diet $x$ Test interaction [F2,28=0.8, $p=0.42]$. However, the number of clusters for maltodextrin non-significantly increased (PR to NR) or decreased (NR to PR) with diet switch (2-way ANOVA: Diet x Test interaction [F2,28=4.3, $p=0.02]$; all Dunnett's post hoc $p>0.06$ ). Data are expressed as mean + SEM. \# $p<0.05$ (one sample t-test versus $50 \%$ ), $\uparrow p<0.05$ and $\dagger \dagger p<0.01$ (2-way ANOVA followed by Dunnett's post hoc tests versus preference test 1 ), ${ }^{*} p<0.05$ (2-way ANOVA followed by Sidak's post hoc tests NR vs. PR). 